\title{
Digital Russia Studies: An Introduction
}

\section{Daria Gritsenko, Mikhail Kopotev, and Mariëlle Wijermars}

\subsection{Area Studies Go Digital}

The "digital" is profoundly changing Russia today. While in the mid-1990s less than 1 per cent of the Russian population had Internet access, today Russia ranks sixth globally with approximately 110 million Internet users, or three quarters of the population (The World Factbook 2019). The proliferation of affordable smartphones in the 2010s has made Internet access a common place by 2020 , with over 60 per cent of users connecting through mobile devices, and Russia's Internet market is the largest in Europe (GfK 2019). According to the Russian Ministry of Digital Development, Communications and Mass Media, the Russian Internet industry amounted to an estimated value of five trillion rubles in 2019, or 5 per cent of the country's gross domestic product (GDP) (TASS 2019). Taking into account the additional 25 million Russians who live outside of Russia, it is no surprise that Russian is the second most

The names of the authors are given in alphabetical order.

D. Gritsenko

University of Helsinki, Helsinki, Finland

e-mail: daria.gritsenko@helsinki.fi

M. Kopotev

Higher School of Economics (HSE University), Saint Petersburg, Russia

e-mail: mkopotev@hse.ru

M. Wijermars $(\bowtie)$

Maastricht University, Maastricht, The Netherlands

e-mail: m.wijermars@maastrichtuniversity.nl 
popular language on the Net after English (Historical trends 2019). These figures alone make Russia an attractive object for researchers interested in the development of today's digital society. The Russian information technologies (IT) industry, moreover, is an ample provider of highly sophisticated digital tools and well-organized software solutions: Nginx's popular web server that is used by, for instance, Netflix; Kaspersky antivirus software; optical character recognition application ABBYY FineReader, to mention just a few. In Russianspeaking markets, tech conglomerate Yandex furthermore successfully rivals with Google, while social networking sites VK (formerly known as VKontakte) and Odnoklassniki outperform their international competitor Facebook.

The global digitalization trend and the major societal shifts that accompany the process of converting ever more information and communications into digital form, challenge and transform existing practices across all spheres of life. In many ways, the digital transformation Russia is undergoing is far from unique. For example, the Russian government, similar to governments elsewhere, actively develops digital strategies, looking to reform education, finances and telecommunications and to increase governmental efficiency. Russian businesses seek to reap the benefits afforded by information and communication technologies (ICTs) and big data as they operate in and expand into domestic and global markets. Russian citizens, meanwhile, actively engage in the production and consumption of web-based content, while their dealings with state authorities increasingly occur through online e-government portals. New trends and practices emerge in the arts, where literary authors experiment with virtual personae and hyperlinked narration, while visual artists explore collaborative and cooperative online work and digital forms of expression.

At the same time, the impact of and responses to these digitalization practices in Russia are evidently context driven. The conservative and authoritarian turn in Russian politics (Smyth 2016) during Vladimir Putin's third presidential term (2012-2018), for example, has influenced not only the political, but also the technological landscape. State attempts to control the online sphere have materialized in various forms, including the regulation of data flows and the blocking of access to unfavorable online content and unruly platforms. Russia also exerts pressure on major domestic and international Internet companies, for example to transfer personal data of Russian citizens to servers located in Russia, and seeks to shape global Internet governance to reflect its favored terms. At the same time, digital communications have created new opportunities for the facilitation of civic resistance, as is evidenced by the success of oppositional leader Alexei Navalny in rallying support and mobilizing political resistance through his online activities.

For researchers investigating Russia, digitalization has resulted in the emergence of a wealth of new (big) data sources, including social media and other kinds of digital-born content that allow us to investigate Russian society in novel ways. The accelerating speed at which Russian archives are being digitized means that collections of research materials have become more easily available, while simultaneously new methodological possibilities open up for examining Russian historical sources with the help of digital tools. The 
abundance of computational methods, ranging from simple automated keyword sorting to complex machine learning algorithms, allow us to tap into the opportunities offered by combining different types of data that have not previously been used together, or to explore patterns in large datasets that are difficult to grasp with a "manual" approach.

Given the intricate combination of the universal and the particular in how Russia is influenced by the digital as well as gives shape to digitalization trends, and the specificities involved in the availability and use of digital sources and methods, we argue that an area studies approach is both timely and productive. Area studies, as we know them today, developed in American and Western European universities in the second half of the twentieth century, when departments studying non-Western cultures welcomed sociology, economics, and political science specialists to, together with language and literature scholars, explore the contemporary social life of the regions they studied (Colonomos $2016,65)$. The value of area studies, essentially a Cold War project striving to provide a general framework to describe and explain what was going on in different parts of the non-Western world, be it the Soviet Block, the Middle East, Africa, Latin America, or China (Rafael 1994), was increasingly questioned after "the end of history" (Fukuyama 1989). The forces of globalization, the third wave of democratization, and the worldwide triumph of the market economy were expected to diminish the value and necessity of studying an area, with its emphasis on contexts; disciplinary knowledge was thought to be central and contextualized "place knowledge" secondary. This volume asserts that area studies, as a geographically and geopolitically motivated interdisciplinary research domain, is of particular value to and can provide a general framework for describing the variety of responses to digitalization and explaining the mechanisms that assist or obstruct the domestication of global trends. In this respect, we can build upon earlier efforts in this direction, such as the volume Digital Russia: The Language, Culture and Politics of New Media Communication (2014) edited by Michael Gorham, Ingunn Lunde, and Martin Paulsen and the journal Studies in Russian, Eurasian and Central European New Media (digitalicons.org). Other area studies fields have similarly turned their attention to digitalization. Consider, for example, the launch of the Digital America journal in 2012 and publications such as The Other Digital China by J. Wang (2019). All such emerging digital area studies initiatives, in turn, draw upon and contribute to the by-now-established field of Internet Studies, exemplified by, for example, The Oxford Handbook of Internet Studies (2013).

The fact that digitalization started making major headline appearances around the same time the post-Cold War end of history was declared is instructive for understanding how it came to be viewed (even though the process of converting traditional forms of information storage and processing into the binary code of computer storage can be traced back to the advent of computing after the Second World War). The ideals closely connected to the early development of the Internet, such as freedom, decentralized control, the claim of universality of technological development and so on, fitted well with the overall narrative of global modernity (Dirlik 2003). Yet, during the past decade 
we have witnessed backlashes on all "global fronts"-including democratic backsliding, the rise of populism, the return of economic protectionism and borders, first off- and then online-allowing area studies to make a comeback. More than half a century of area studies scholarship has brought forward important methodological accomplishments that turn out to be extremely useful in approaching these global backlashes. First, the idea that context matters, a staple in the disciplines of geography and anthropology, has been explicitly brought into studies on economics, politics, and society through in-depth field research. Area studies have routinely challenged the US- and Euro-centric assumptions of many disciplines, while Szanton (2004) even argued that mainstream disciplines are in fact special cases of area studies, American and European Studies, respectively. Practices of place-based research that produce contextually and culturally rooted explanations are useful if we seek to fully understand questions of digital transformation.

Second, the multi- and interdisciplinary approaches that are inherent to research projects in area studies have led to extensive conceptual borrowing, cross-fertilization among disciplinary fields, and an emphasis on comparative methodologies (Katzenstein 2001). Practical circumstances-colleagues working at centers for area studies are likely to have various disciplinary backgrounds and area studies conferences bring together scholars working across the humanities and social sciences-not only push individual scholars out of their (disciplinary) comfort zone, but also provide ideas and nourish creative conceptual development. This feature, we want to suggest, is invaluable for studying digitalization across societies. Finally, language, which has been at the center of area studies from its very inception, has been recognized "as productive and powerful in its own right" (Gibson-Graham 2004) and capable of shaping social practices. Accentuating the performativity of language and the power of discourse as a method for critical deconstruction, area studies have been at the forefront of the so-called interpretative turn in the social sciences. By the same token, language-based approaches-in particular computational approaches-are among the backbones of digital studies.

Therefore, it makes sense to talk about Digital Russia Studies. Yet, a comprehensive volume that offers novice-friendly guidance for navigating the full breadth of this new territory is currently lacking. To grasp the simultaneous transformation of research object and research practices, this Handbook brings together world-leading experts and emerging scholars to lead the way in the emerging field of Digital Russia Studies. That being said, we are moving away from the conventional label of Russian Studies to highlight that we aim to contribute to and consolidate a methodological broadening in area studies: Digital Russia studies focuses on the digital transformation of the (geographical) area of study, while digital Russia Studies indicates the use of digital sources and methods in studying it and that is only partially captured by the term "digital humanities." Together, Digital Russia Studies emphasizes how these two research lines are intertwined, interdependent, and mutually reinforcing. 
Drawing the borders of Digital Russia is no easy feat, even though it is clear that it cannot be reduced to the digital projection of the state within its physical borders. For one, many political and economic digital actors of significance are located outside Russia, for example online media outlet Meduza that operates from Latvia and Yandex N.V. that is registered in the Netherlands. Russian services also operate in languages other than Russian and are not merely hosted on the Russian .ru domain, but also on international domains (such as .com or .edu) and the still functional Soviet .su domain. Russian Studies for the digital era therefore deals with opaque, negotiable, and constantly moving bordersmaterial and virtual - that cannot be set once and for all, but rather require careful consideration depending on the case-study, level of analysis, or specific research application.

Aiming to present a multidisciplinary and multifaceted perspective on the issues outlined above, the objective of this Handbook is twofold, as reflected in its two-part structure. The first part of the book, Studying Digital Russia, provides a critical and conceptual update on how Russian society, politics, economy, and culture are reconfigured in the context of digitalization, datafication, and the - by now-widespread use of algorithmic systems. Reviewing the state of the art in scholarship on a broad range of policy sectors and issues, the chapters investigate the transformative power of the digital and the particularities of how these transformations manifest themselves in the context of Russia. The chapters also reflect on societal responses to these ongoing transformation processes.

The second part of the Handbook, Digital Sources and Methods, combines two subsections that aim to answer practical and methodological questions in dealing with Russian data. Digital Sources describes the main resources that are available to investigate the multifaced Digital Russia sketched above: textual, visual, and numeric. In addition, the vulnerabilities, uncertainties, legal and ethical controversies involved in working with Russian digital materials are addressed. The second subsection, Digital Methods, showcases examples of cutting-edge digital methods applied in different fields of research. The chapters provide a concise overview of the manifold opportunities for studying society, politics, and culture in novel ways. The chapters also address the particular methodological issues that researchers will encounter when working with Russian data, such as working with Russian social media platforms and processing sources written in Cyrillic rather than Latin script. The chapters in this section demonstrate how the area studies tradition of invoking context as an essential element of scientific explanation can leverage some of the criticism that is being directed to the use of digital methodologies and big data in humanities and social sciences research. In the remainder of this introduction, we provide an overview of the topics, questions, and methods covered by the contributions in this Handbook and briefly sketch the emergence of digital technologies and networks in the region. 


\subsection{Studying Digital Russia}

The first attempts to establish a national digital network in Russia can be traced back to the late Soviet period and the never realized project called OGAS

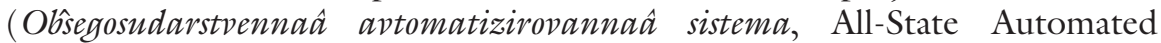
System). As is recounted by Benjamin Peters (2016), the story of OGAS is a troubled one that ended in total failure due to the forces of Soviet bureaucracy, effectively resisting innovations capable of jeopardizing state power, or the positions of those in power. In the 1990s, local- and national-level networks were overtaken by the expansion of the global Internet, emerging out of the efforts of, for example, research institutions Conseil Européen pour la Recherche Nucléaire (CERN) in Switzerland and the Institute for High Energy Physics in Russia (Abbate 1999; Gerovitch 2002). Since then, global technological developments have followed similar trends, albeit at different paces; for example, the transitions from low- to high-speed Internet, from wired to wireless access, and from expensive to affordable services offered by Internet service providers. While the Internet was becoming more user-friendly, functional and attractive all around, its social and political domestication in Russia had its specificities: whereas many Western publicly available online services were developed by IT geeks in garages, the Russian Internet, as legend has it, was born in the kitchens of the intelligentsia. This local feature is sealed in the term "Runet" coined from the words "Russian" and "Internet."

The concept of Runet has evolved over the course of the past decades, along with the object it describes, as Asmolov and Kolozaridi explain in their chapter. Yet, in any circumstance it cannot be reduced to the ru-domain or to online content in the Russian language. In the late 1990s-early 2000s, when the concept gained a foothold, Runet was defined as having two fundamental features: it was logocentric and free. The first feature refers to the fact that many of Runet's forerunners had an interest in the arts and humanities:

The RuNet is specific with regard to the topic of literature: the myth of 'literaturecentrism' of Russian culture (almost dead, as it seems) has been resurrected on the RuNet's literary sites, which have no analogues in the other (national) segments of the Internet. (Konradova et al. 2006)

The first Runet websites, for example lib.ru, while technologically and economically amateurish, were oriented toward the free distribution of information and deeply rooted into the domestic cultural context. Many of these features are still preserved in Runet today (see Chaps. 15 and 9), even though it has become technologically advanced and market oriented, as the chapter by $\mathrm{O}$. Gurova and Morozova on digital consumption shows. Runet preserves some of the spirit of freedom, although the legality of some of these activities can be questioned (see Chaps. 7,8 and Chap. 6). Digital technologies have 
given a great impetus to innovation of the arts, as Strukov demonstrates in his chapter. The Internet has also been instrumental in facilitating the expression and negotiation of gender identities, analyzed by Andreevskikh and Muravyeva, and is leaving its mark on religious practices, as Khroul's chapter demonstrates.

In its early days, the Internet in Russia developed practically free from state interference. As many sources testify (e.g. Babaeva 2015), soon-to-be president Vladimir Putin hosted a meeting with representatives of the IT (information technologies) industry on December 28, 1999, during which the sector was promised a decade of free development. Limited state regulation and meddling indeed was among the defining features of Runet for a considerable period of time (e.g. the lack of effective online copyright protection), but the screws have been steadily tightening, most rapidly from 2012 onwards, as is addressed in multiple chapters in this volume (e.g. Chaps. 16, 8 and 2). The Russian Internet has come under ever more direct and indirect control of the state, among others in terms of extensive surveillance capabilities and prerogatives concerning digital communications and the economic dependence of IT businesses. In 2019 alone, there have been several milestone decisions that illustrate the extend of state control over how the Internet develops in Russia. For example, the expansion of $5 \mathrm{G}$ network technology has been significantly delayed because of continued resistance, among others by the Security Council of the Russian Federation, against making the preferred frequency band available for civilian uses (the 3.4-3.8 GHz range earmarked for 5G use by, e.g. European Union [EU] countries, is currently used by the Russian military and security services), while Yandex changed its corporate governance structure to accommodate governmental pressure and avert the introduction of legislation limiting foreign ownership of major Internet companies (Yandex N.V. is registered in the Netherlands).

While the Russian government has sought to counteract the freedoms previously afforded to the Internet through regulation and other control strategies, the analyses in the first part of the Handbook make clear how it at the same time recognizes the enormous potential of digital technologies. Indeed, the Russian government frequently points toward digitalization as a cornerstone of the country's development. At the 2017 Saint Petersburg Economic Forum, for example, Putin highlighted Russia's place among the forefront of research into artificial intelligence $(\mathrm{AI})$ :

Just like other leading nations, Russia has drafted a national strategy for developing $\mathrm{AI}$ technologies. It was designed by the Government along with domestic hi-tech companies. (http://en.kremlin.ru/events/president/news/60707, official translation)

The federal government runs various programs to support digitalization across sectors, such as government (analyzed by Gritsenko and Zherebtsov), politics (discussed by Wijermars), law and justice (addressed by Muravyeva and Gurkov), economy (examined by Lowry), and education (analyzed by Piattoeva 
and G. Gurova). Billions of rubles from the federal budget have been invested into infrastructure, making available many e-services, as well as an abundance of administrative, legislative, archival, textual, geospatial data (explored in Part II of this volume). As the chapters in this Handbook discuss in more detail, the success of these federal programs is ambivalent. It is however undeniable that the massive amount of data that is produced by various agencies as a result is now available to experts and citizen scientists alike, enabling them to conduct in-depth big data analyses, among others to reveal breakdowns in governance (as is argued by Parkhimovich and Gritsenko, and Kopotev, Rostovstev, and Sokolov in their respective chapters).

The ostensibly clear-cut image of Russia's Internet status changing from free to not free over the course of the past two decades, as is evidenced by annual rankings of Internet freedom, therefore fails to tell the full story and its inherent paradoxes. Manifold examples demonstrate how the Internet continues to be instrumental for facilitating civic resistance, as Lonkila et al. recount in their analysis. From this perspective, today's digital dissidents can be seen as acting in the vein of the Soviet intelligentsia, even though the two groups represent different generations and values.

\subsection{Digital Sources and Methods}

The second part of the Handbook is diverse and of a more applied nature. It starts with chapters discussing the most widely used digital sources, mainly those for text-based studies that depart from the assumption that language can be studied as a reflection of society. Collections of texts, or textual corpora, are a key resource for linguistic studies as well as for a wide variety of applications within the humanities and social sciences. Kopotev, Mustajoki, and BonchOsmolovskaya describe these sources with a focus on the Russian National Corpus (RNC), a deeply annotated and well-designed resource on the Russian language, and the Integrum database, which comprises most newspapers, journals, and online media published in Russia or in Russian, as well as TV and radio transcripts. Thesauri, for example the Russian RuThes thesaurus that is discussed by Loukachevitch and Dobrov, are more sophisticated linguistic and terminological resources for automatic text processing that can be used to explore concepts, changes in word meaning, text categorization, and so forth. More recently, social media have established themselves as a new channel of communication and novel resource for studying a wide set of societal questions. In a chapter that focuses on assessing the applicability of existing models of social media research in the Russian context, Koltsova et al. present the limitations of existing approaches and suggest best practices for social media research that uses Russian sources.

Two chapters are devoted to digital archives and digitized archival materials. While all standard text-analytical techniques, both qualitative and quantitative, can be applied to these materials, the contributions draw attention to questions 
regarding their provenance, objectivity, and affordances, and the complex political economy of historical knowledge production. Providing an overview of digitization practices in Russia, Golubev reveals an underlying political agenda to restore epistemic sovereignty over Russian history. Kalinina, in turn, raises a series of techno-methodological questions concerning the composition and affordances of a digital archive platform created by a community of volunteers. The final digital source covered is open government data, which is presented by Parkhimovich and Gritsenko from an infrastructural, legal, and technical viewpoint. Illustrating their argument with examples of projects and applications utilizing open government data, especially open financial data, the authors provide concrete use cases that show the perceived benefits for government agencies and citizens.

The final collection of chapters is methodological in orientation, presenting a variety of digital and computational techniques and providing concrete examples of their use in Russian Studies. First, topic modeling, a method of probabilistic text clustering, is explored. Bodrunova looks at how topic modeling techniques have been developed and employed by Russian scholars-applied both to Russian and other languages - paying special attention to questions of validity and assessment of model quality. Oiva shows how topic modeling can be applied to Russian historical sources - such as Soviet newspapers-and offers an accessible step-by-step walk through of the basics of topic modeling. Indukaev then applies topic modeling to a contemporary media collection obtained from the Integrum database and showcases how the analysis can be enriched by incorporating the word embedding technique. He argues that the latter is capable of providing more accurate observations of the data. Artemova dives even deeper into Natural Language Processing (NLP). She focuses on deep-learning applications for processing Russian, presenting state-of-the-art methods in the field. The chapter written by Kopotev, Rostovtsev, and Sokolov investigates the issue of academic plagiarism and how its detection posits a challenge for computational linguistics. Another popular NLP applicationsentiment analysis - is discussed by Loukachevitch, who explains the main contemporary applications of the method focusing on Russian-specific components of automatic sentiment analysis.

While computational text-analytical techniques constitute the backbone of Digital Russia Studies, other methods provide equally exiting opportunities for future research. The first of these is network analysis, a method for exploring relationships and structures based on graph theory. To show the versatility of its application, we have included two chapters. Fischer and Skorinkin apply network analysis in the field of literary studies. They demonstrate how texts can be formalized into a set of nodes and edges, where nodes represent characters and edges describe interactions between these characters, based on a selection of Russian plays and the classic novel War and Peace by Leo Tolstoy. The second application concerns a study of Russian politics and society on microblogging platform Twitter. Zherebtsov and Goussev analyze six resonant political 
events to demonstrate how network analysis enables an alternative approach to answer classic questions within political science, such as designating political communities, tracing group reactions to informational events, and detecting opinion leaders and influencers.

The Handbook concludes with two methods that operate with nontextual data. The field of art history, Kangas argues, has lagged behind in joining the digital humanities trend; yet, digital image analysis opens up various new avenues for research. Drawing upon the example of Soviet political cartoons, she advocates the use of mixed methods to best utilize computational and human interpretative strengths. The final chapter is devoted to the analytical use of geospatial data, their attributes in Russia's online ecosystem, and the methodologies best suited for their analysis. Makhortykh discusses novel techniques for extracting geolocations from various data formats and demonstrates different ways of using these data, from mapping the spatial distribution of social and political phenomena to the use of the geoweb for narrating individual and collective identities online.

\subsection{Concluding Remarks}

With this Handbook we have aimed to lay down the foundations for the emerging research direction of Digital Russia Studies. Through its 32 chapters, the book makes a timely intervention in our understanding of the changing field of Russian Studies at the intersection of the societal and the digital in order to become a first comprehensive review and guide for scholars as well as graduate and advanced undergraduate students studying Russia today.

As is true for any work that seeks to carve out the contours of an emerging field of study, the range of topics, approaches, and methods covered in this Handbook is necessarily incomplete. However, by compiling analyses of the impact of digitalization on various spheres of Russian politics, society, and culture in a single volume together with chapters exemplifying best practices in using digital sources and methods in Russian Studies, we hope to have demonstrated the value of an area studies approach in studying the digital domain. At the same time, it has to be acknowledged that this Handbook is itself a product and expression of the shifts we are currently witnessing: while most analyses included here are still predicated to some extent on the opposition between, coexistence, and interwovenness of digital and analogue, such distinctions may rapidly become obsolete as digital becomes the new norm in ever more domains. In this regard, the Handbook also functions as an important landmark, documenting these transitional pathways as they take shape across various spheres of society and human activity. 


\section{REFERENCES}

Abbate, Janet. 1999. Inventing the Internet. Cambridge, MA: MIT Press.

Babaeva, Svetlana. 2015. Interv'û s Antonom Nosikom [Interview with Anton Nosik]. Accessed December 10, 2019. https://www.gazeta.ru/social/2017/07/09/ 10779572.shtml.

Colonomos, Ariel. 2016. Selling the Future: The Perils of Predicting Global Politics. London: Hurst.

Dirlik, Arif. 2003. Global Modernity? Modernity in an Age of Global Capitalism. European Journal of Social Theory 6 (3): 275-292.

Dutton, W.H., ed. 2013. The Oxford Handbook of Internet Studies. Oxford: Oxford University Press.

Fukuyama, Francis. 1989. The End of History? The National Interest 16: 3-18.

Gerovitch, Slava. 2002. From Newspeak to Cyberspeak: A History of Soviet Cybernetics. Cambridge, MA: MIT Press.

GfK. 2019. Issledovanie GfK: Proniknovenie interneta v Rossii [GfK Research: Internet Penetration in Russia]. Accessed December 16, 2019. https://www.gfk.com/ru/ insaity/press-release/issledovanie-gfk-proniknovenie-interneta-v-rossii.

Gibson-Graham, Julie. 2004. Area Studies After Post-structuralism. Environment and Planning A 36 (3): 405-419.

Gorham, Michael, Ingunn Lunde, and Martin Paulsen. 2014. Digital Russia: The Language, Culture and Politics of New Media Communication. Abingdon and New York: Routledge.

Historical trends. 2019. Historical Trends in the Usage of Content Languages for Websites. Accessed December 16, 2019. https://w3techs.com/technologies/history_overview/content_language.

Katzenstein, Peter. 2001. Area and Regional Studies in the United States. PS: Political Science and Politics 34 (4): 789-791.

Konradova, Natalja, Henrike Schmidt, and Katy Teubener, eds. 2006. Control+Shift: Public and Private Usages of the Russian Internet. Norderstedt: BOD Verlag.

Peters, Benjamin. 2016. How Not to Network a Nation: The Uneasy History of the Soviet Internet. Cambridge, MA: MIT Press.

Rafael, Vicente L. 1994. The Cultures of Area Studies in the United States. Social Text 41: 91-111.

Smyth, Regina. 2016. Studying Russia's Authoritarian Turn: New Directions in Political Research on Russia. Russian Politics 1 (4): 337-346.

Szanton, David L. 2004. Introduction: The Origin, Nature, and Challenges of Area Studies in the United States. In The Politics of Knowledge: Area Studies and the Disciplines, ed. D. Szanton. Berkley: University of California Press.

TASS. 2019. V Minkomsvâzi ocenili ob"em èkonomiki Runeta [The Ministry of Communications Estimated the Volume of the Runet Economy]. Accessed January 11, 2020. https://tass.ru/ekonomika/7016909.

The World Factbook. 2019. Washington, DC: Central Intelligence Agency. Accessed December 10, 2019. https://www.cia.gov/library/publications/resources/theworld-factbook/index.html.

Wang, Jing. 2019. The Other Digital China: Non-confrontational Activism on the Social Web. Cambridge: Harvard University Press. 
Open Access This chapter is licensed under the terms of the Creative Commons Attribution 4.0 International License (http://creativecommons.org/licenses/ by/4.0/), which permits use, sharing, adaptation, distribution and reproduction in any medium or format, as long as you give appropriate credit to the original author(s) and the source, provide a link to the Creative Commons licence and indicate if changes were made.

The images or other third party material in this chapter are included in the chapter's Creative Commons licence, unless indicated otherwise in a credit line to the material. If material is not included in the chapter's Creative Commons licence and your intended use is not permitted by statutory regulation or exceeds the permitted use, you will need to obtain permission directly from the copyright holder. 